\title{
Comparing the effects of root surface scaling with ultrasound instruments and Er,Cr:YSGG laser
}

\author{
Zohre Tabibzadeh Noori • Reza Fekrazad • \\ Behnam Eslami • Ardavan Etemadi • \\ Shabnam Khosravi • Maziar Mir
}

Published online: 13 November 2007

(C) Springer-Verlag London Limited 2007

The present address of the author Behnam Eslami was missing. It is as given here:

Department of Oral Medicine, Infection and Immunity,

Harvard School of Dental Medicine

188 Longwood Avenue

Boston, MA 02115, USA

The online version of the original article can be found at http://dx.doi. org/10.1007/s10103-007-0480-8.

\footnotetext{
Z. T. Noori · A. Etemadi

Department of Periodontology, Faculty of Dentistry,

Shaheed Beheshti Medical University,

Tehran, Iran

R. Fekrazad

Laser Research Centre, Faculty of Dentistry,

Shaheed Beheshti Medical University,

Tehran, Iran

B. Eslami

Department of Pathology, Faculty of Dentistry,

Shaheed Beheshti Medical University,

Tehran, Iran

S. Khosravi

Private practice,

Tehran, Iran

M. Mir $(\bowtie)$

Department of Conservative Dentistry,

Periodontology and Endodontics, Aachen RWTH Hospital,

Pauwelsstr. 30,

52074 Aachen, Germany

e-mail: mmir@ukaachen.de

Present address:

B. Eslami

Department of Oral Medicine, Infection and Immunity,

Harvard School of Dental Medicine,

188 Longwood Avenue,

Boston, MA 02115, USA
} 